\title{
UM ESTUDO SOBRE OS GÊNEROS TEXTUAIS NO APOSTILADO DE LÍNGUA PORTUGUESA DA REDE PÚBLICA PAULISTA
}

\author{
A STUDY ON THE TEXT GENRES IN THE PORTUGUESE LANGUAGE WORKBOOK FOR \\ THE STATE OF SÃO PAULO PUBLIC NETWORK
}

\author{
Paulo Roberto Barbosa ${ }^{1}$ \\ ${ }^{1}$ Secretaria Municipal de Educação de Poá, São Paulo, SP, Brasil \\ paulobarbosa2709@gmail.com
}

Recebido em 24 jun. 2018

Aceito em 23 ago. 2018

\begin{abstract}
Resumo: Este estudo trata da análise das questões referentes ao ensino dos gêneros textuais presentes no Caderno do Aluno de Língua Portuguesa do 9ํano do Ensino Fundamental, apostilado distribuído na rede pública de ensino do estado de São Paulo. Sua abrangência e consequente relevância no panorama educacional do estado motivaram nossa escolha por analisá-lo, visto que as apostilas são utilizadas pelos alunos da rede oficial de ensino. $O$ objetivo que norteia esta pesquisa é levantar os gêneros textuais que estão presentes no Caderno do Aluno de Língua Portuguesa, uma vez que, as resoluções dos Parâmetros Curriculares Nacionais (BRASIL, 1998) - no que concerne às sugestões para o ensino da Língua Portuguesa, a partir das quais foi elaborado o Currículo do Estado de São Paulo (SÃO PAULO, 2012), sugerem que, no 9o ano do Ensino Fundamental, sejam estudados com maior ênfase os textos argumentativos e expositivos. Para isso, o estudo considera o ensino com base em gêneros textuais propostos por Bakhtin (2011 [1979]) e reinterpretados pelo viés teórico-metodológico de Bronckart (2012 [1997]), Marcuschi (2008) e Dolz e Schneuwly (2004), segundo os quais a linguagem é uma forma de ação que se realiza no discurso socialmente situado e partilhado por meio dos gêneros textuais.
\end{abstract}

Palavras-chave: Gêneros textuais. Parâmetros Curriculares Nacionais. Currículo do Estado de São Paulo.

Abstract: This study deals with the analysis of the questions related to the teaching of the textual genres present in the Notebook of the Portuguese Language Student of the 9th year of Elementary School, an apostille distributed in the public teaching system of the state of São Paulo. Its scope and consequent relevance in the educational panorama of the state motivated our choice to analyze it, since the handbooks are used by the students of the official network of education. The objective of this research is to raise the textual genres that are present in the Portuguese Language Student Notebook, since the resolutions of the National Curricular Parameters (BRASIL, 1998) - with regard to suggestions for teaching Portuguese, from which the São Paulo State Curriculum (SÃO PAULO, 2012) was elaborated, suggest that, in the 9th year of elementary school, the argumentative and expository texts should be studied with greater emphasis. For this, the study considers teaching based on textual genres proposed by Bakhtin (2011 [1979]) and reinterpreted by the theoretical-methodological bias of Bronckart (2012 [1997]), Marcuschi (2008) and Dolz and Schneuwly (2004), according to which language is a form of action that takes place in discourse socially situated and shared through textual genres.

Keywords: Textual genres. National Curricular Parameters. Curriculum of the State of São Paulo. 


\section{Introdução}

Este artigo é resultado de uma dissertação de mestrado que trata dos gêneros textuais presentes no Caderno do Aluno de Língua Portuguesa (CALP).

As pesquisas acerca dos gêneros textuais estão recebendo cada vez mais atenção do meio acadêmico, e os resultados desses trabalhos já estão influenciando, de certa forma, as configurações das aulas de Língua Portuguesa no Brasil. De acordo com os Parâmetros Curriculares Nacionais (PCN) (BRASIL, 1998), o estudo dos gêneros textuais deve ter como objetivo potencializar o ensino da linguagem de forma ampla, sem se limitar apenas a aspectos gramaticais ou prescritivos, proporcionando ao aluno 0 desenvolvimento e o refinamento das habilidades linguísticas para se tornar um agente capaz de selecionar e de produzir enunciados nos mais variados contextos comunicativos.

Com a finalidade de tentar alcançar esses objetivos, o Governo do Estado de São Paulo adotou o sistema de apostilado na rede pública de ensino, o qual respeita, sobretudo, as orientações do Currículo do Estado de São Paulo (CESP) (SÃO PAULO, 2012) - acerca dos conteúdos a serem vistos em cada ciclo.

O conteúdo do apostilado é dividido em dois volumes, cada qual dedicado a um dos semestres do ano letivo. O material é organizado por temas que seguem as orientações do CESP (SÃO PAULO, 2012), com foco em determinadas tipologias textuais em cada ano letivo e com execução de atividades e projetos envolvendo o conteúdo abordado. Vale evidenciar que utilizamos o quadro geral proposto por Marcuschi (2008, p. 194-196) para enquadrar os gêneros textuais encontrados no CALP.

\section{Gênero Textual}

A noção de gêneros tal qual conhecemos hoje começou a ser elaborada por Bakhtin (2011 [1979]). De acordo com o estudioso, todos os enunciados representados por meio da oralidade ou da escrita são determinados, em princípio, por suas características particulares e pelos objetivos aos quais 
obedecem. Em suas palavras, "[...] cada enunciado particular é individual, mas cada campo de utilização da língua elabora seus tipos relativamente estáveis de enunciados, os quais denominamos gêneros do discurso" (BAKHTIN, 2011, p. 262 [1979], grifos do autor).

Enquanto Bakhtin (2011 [1979]) emprega a expressão "gêneros do discurso", Bronckart (2012 [1997]) prefere o termo "gêneros de texto", justificando essa preferência ao afirmar que as modalidades discursivas são, na realidade, componentes de uma estrutura textual. Vale lembrar que adotamos a expressão gêneros textuais ancorados na argumentação de Marcuschi (2008) de não discutir qual é a mais pertinente das escolhas, mas adotar a posição de que todas elas (gênero discursivo, gênero do discurso, gênero textual e gênero de texto) podem ser utilizadas intercambiavelmente, salvo naqueles casos em que se pretende identificar algum evento específico.

Em relação a tais concepções, encontramos consonância com as pesquisas de Marcuschi (2005), segundo o qual "os gêneros textuais são fenômenos históricos, profundamente vinculados à vida cultural e social. Fruto de trabalho coletivo, os gêneros contribuem para ordenar e estabilizar as atividades comunicativas do dia a dia." (MARCUSCHI, 2005, p. 19).

Compreende-se, pois, o caráter funcional dos gêneros como elementos comunicativos e institucionalizados. Por esse mesmo motivo, o texto não se constitui isoladamente, sem que haja uma interação social, e é exatamente essa característica de dependência das situações coletivas que garante a ele a versatilidade e maleabilidade de função. Os gêneros são incontáveis e, mesmo os mais convencionais, carregam consigo a flexibilidade de uma entidade social, um organismo vivo e mutável que responde aos contextos nos quais se insere.

O ensino com base em gêneros textuais deve ser pautado na importância de fazer o aluno identificar e entender as expectativas dos ouvintes e escritores quanto a seu texto, sua forma, seu conteúdo, dentre outros. Dessa forma, faz-se necessário compreender o que é gênero. Segundo Dolz e Schneuwly (2004, p. 142), gêneros são "[...] formas relativamente estáveis de textos que funcionam como intermediárias entre o enunciador e o destinatário", ou seja, os gêneros fazem com que a comunicação se efetue, já que seria 
muito complexo para o enunciador ter de criar, inventar estruturas linguísticas e contextuais para cada situação de comunicação.

Vale lembrar que utilizamos o quadro geral a seguir, proposto por Marcuschi (2008, p. 194-196), para enquadrar os gêneros textuais localizados no CALP. Evidenciamos, ainda, que a escolha do quadro geral se justifica pela tentativa de didatizar o levantamento dos gêneros textuais encontrados no CALP. Encontramos, em nossa tabulação de dados, a existência de alguns gêneros que não se enquadram no quadro geral proposto pelo autor. $O$ agrupamento proposto por Marcuschi é reproduzido no Quadro 1, a seguir:

\section{QUADRO 1 - Domínios Discursivos e Gêneros Textuais}

\begin{tabular}{|c|c|c|}
\hline \multirow{2}{*}{$\begin{array}{l}\text { DOMíNIOS } \\
\text { DISCURSIVOS }\end{array}$} & \multicolumn{2}{|c|}{ MODALIDADES DE USO DA LÍNGUA } \\
\hline & Escrita & Oralidade \\
\hline $\begin{array}{l}\text { INSTRUCIONAL } \\
\text { (científico, acadêmico } \\
\text { e educacional) }\end{array}$ & $\begin{array}{l}\text { artigo científico; verbete de enciclopédia; relatório científico; } \\
\text { notas de aula; nota de rodapé; diário de campo; tese; } \\
\text { dissertação; monografia; glossário; artigo de divulgação } \\
\text { científica; tabela; mapa; gráfico; resumo de artigos de livros; } \\
\text { resumo de livro; resumo de conferência; resenha; } \\
\text { comentários; biografia; projetos; solicitação de bolsa; } \\
\text { cronograma de trabalho; organograma de atividade; } \\
\text { monografia de curso; monografia de disciplina; definição; } \\
\text { autobiografia; manual de ensino; bibliografia; ficha } \\
\text { catalográfica; memorial; curriculum vitae; parecer técnico; } \\
\text { verbete; parecer sobre tese; parecer sobre artigo; parecer } \\
\text { sobre projeto; carta de apresentação; carta de } \\
\text { recomendação; ata de reunião; sumário; índice remissivo; } \\
\text { diploma; índice onomástico; dicionário; prova de língua; } \\
\text { prova de vestibular; prova de múltipla escolha; diploma; } \\
\text { certificado de especialização; certificado de proficiência; } \\
\text { atestado de participação; epígrafe }\end{array}$ & 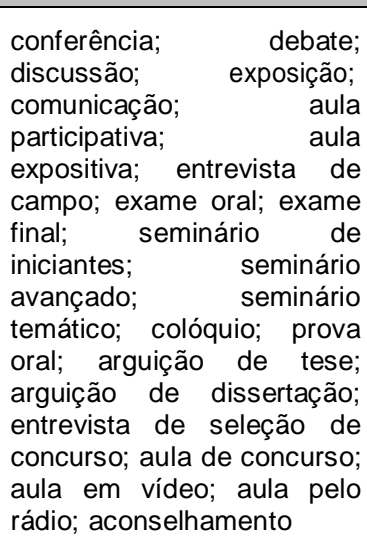 \\
\hline JORNALÍSTICO & $\begin{array}{l}\text { editorial; notícia; reportagem; nota social; artigo de opinião; } \\
\text { comentário; jogos; história em quadrinhos; palavra cruzada; } \\
\text { crônica policial; crônica esportiva; entrevista jornalística; } \\
\text { anúncios classificados; anúncios fúnebres; carta do leitor; } \\
\text { carta ao leitor; resumo de novela; reclamações; capa de } \\
\text { revista; expediente; boletim do tempo; sinopse de novela; } \\
\text { resumo de filme; cartoon; caricatura; enquete; roteiros; } \\
\text { errata; charge; programação semanal; agenda de viagem }\end{array}$ & $\begin{array}{l}\text { entrevista } \\
\text { entrevista } \\
\text { entrevista televisisiva; } \\
\text { entrevista coletiva; notícia } \\
\text { de rádio; notícia de TV; } \\
\text { reportagem ao vivo; } \\
\text { comentários; discussões; } \\
\text { debate; apresentações; } \\
\text { programa radiofônico; }\end{array}$ \\
\hline RELIGIOSO & $\begin{array}{l}\text { oração; reza; catecismo; homilia; hagiografia; cântico } \\
\text { religioso; missal; bula papal; jaculatória; penitência; } \\
\text { encíclica papal }\end{array}$ & $\begin{array}{l}\text { sermão; confissão; reza; } \\
\text { cantorias; oração; } \\
\text { lamentações; benzeção; } \\
\text { cantos medicinais }\end{array}$ \\
\hline SAÚDE & $\begin{array}{l}\text { receita médica; bula de remédio; parecer médico; receitas } \\
\text { caseiras; receitas culinárias }\end{array}$ & $\begin{array}{l}\text { consulta; entrevista médica; } \\
\text { conselho médico }\end{array}$ \\
\hline COMERCIAL & $\begin{array}{l}\text { rótulo; nota de venda; fatura; nota de compra; classificados; } \\
\text { publicidade; comprovante de pagamento; nota promissória; } \\
\text { nota fiscal; boleto; boletim de preços; logomarca; } \\
\text { comprovante de renda; carta comercial; parecer de } \\
\text { consultoria; formulário de compra; carta-resposta; comercial; } \\
\text { memorando; nota de serviço; controle de estoque; controle } \\
\text { de venda; copyright; bilhete de avião; bilhete de ônibus; } \\
\text { carta de representação; certificado de garantia; atestado de } \\
\text { qualidade; lista de espera; balança comercial }\end{array}$ & $\begin{array}{l}\text { publicidade de feira; } \\
\text { publicidade de TV; } \\
\text { publicidade de rádio; refrão } \\
\text { de feira; refrão de carro de } \\
\text { venda de rua }\end{array}$ \\
\hline INDUSTRIAL & $\begin{array}{l}\text { instruções de montagem; descrição de obras; código de } \\
\text { obras; aviso; controle de estoque; atestado de validade; }\end{array}$ & ordens \\
\hline
\end{tabular}




\begin{tabular}{|c|c|c|}
\hline & manual de instrução & \\
\hline JURÍDICO & $\begin{array}{l}\text { contrato; lei; regimento; estatuto; certidão de batismo; } \\
\text { certidão de casamento; certidão de óbito; certidão de bons } \\
\text { antecedentes; certidão negativa; atestado; certificado; } \\
\text { diploma; normas; regras; parecer; boletim de ocorrência; } \\
\text { edital de convocação; edital de concurso; aviso de licitação; } \\
\text { auto de penhora; auto de avaliação; documentos pessoais; } \\
\text { requerimento; autorização de funcionamento; alvará de } \\
\text { licença; alvará de soltura; alvará de prisão; sentença de } \\
\text { condenação; citação criminal; mandado de busca; decreto- } \\
\text { lei; medida provisória; desmentido; edital; regulamento; } \\
\text { advertência }\end{array}$ & $\begin{array}{l}\text { tomada de depoimento, } \\
\text { arguição; declaração; } \\
\text { exortação; depoimento; } \\
\text { inquérito judicial; inquérito } \\
\text { policial; ordem de prisão }\end{array}$ \\
\hline PUBLICITÁRIO & $\begin{array}{l}\text { propaganda; publicidade, anúncio, cartaz; folheto; } \\
\text { logomarca; aviso; necrológio; outdoors; inscrições em } \\
\text { muros; inscrições em banheiros; placa, endereço postal; } \\
\text { endereço eletrônico; endereço de internet }\end{array}$ & $\begin{array}{l}\text { publicidade na } \\
\text { publicidade no rádio }\end{array}$ \\
\hline LAZER & $\begin{array}{l}\text { piada; jogos; adivinha; história em quadrinhos; palavra } \\
\text { cruzada; horóscopo }\end{array}$ & $\begin{array}{l}\text { fofoca; piada; adivinha; } \\
\text { jogos teatrais }\end{array}$ \\
\hline INTERPESSOAL & $\begin{array}{l}\text { carta pessoal; carta comercial; carta aberta; carta do leitor; } \\
\text { carta oficial; carta-convite; cartão de visita; e-mail; bilhete; } \\
\text { ata; telegrama; memorando; boletim; relato; agradecimento; } \\
\text { convite; advertência; informe; diário pessoal; aviso fúnebre; } \\
\text { volante; lista de compras; endereço postal; endereço } \\
\text { eletrônico; autobiografia; formulário; placa; mapa; catálogo; } \\
\text { papel timbrado }\end{array}$ & $\begin{array}{l}\text { recado; } \quad \text { conversação } \\
\text { espontânea; telefonema; } \\
\text { bate-papo virtual; convite; } \\
\text { agradecimento; advertência; } \\
\text { aviso; ameaça; provérbio }\end{array}$ \\
\hline MILITAR & $\begin{array}{l}\text { ordem do dia; roteiro de cerimônia oficial; roteiro de } \\
\text { formatura; lista de tarefas }\end{array}$ & ordem do dia \\
\hline FICCIONAL & $\begin{array}{l}\text { épica-lírica-dramática; poema; conto, mito; peça de teatro; } \\
\text { lenda; parlenda; fábula; história em quadrinhos; romance; } \\
\text { drama; crônica; roteiro de filme }\end{array}$ & $\begin{array}{l}\text { fábula; conto; lenda; poema; } \\
\text { declamação; encenação }\end{array}$ \\
\hline
\end{tabular}

Fonte: Adaptado de Marcuschi (2008, p. 194-196).

O autor observa que, na Língua Portuguesa, há uma predominância dos gêneros textuais representados por meio da escrita em detrimento daqueles típicos da oralidade e acrescenta que, se fizéssemos o mesmo trabalho de agrupamento dos gêneros em Domínio Discursivo ${ }^{1}$ considerando outras culturas, os resultados poderiam ser muito diferentes e surpreendentes, reforçando a carga cultural indissociável aos gêneros textuais.

\section{Parâmetros Curriculares Nacionais}

As décadas de 80 e de 90 foram marcadas, no Brasil, pela busca da redemocratização e de revisão dos direitos sociais após a queda do regime militar (1964-1985). Na educação, houve uma série de movimentos estudantis e o surgimento de entidades representativas que promoveram debates sobre as questões educacionais e sobre as políticas públicas para a educação. Além disso, houve o estabelecimento de uma nova Constituição, em 1988, a criação

\footnotetext{
${ }^{1}$ O conceito de domínio discursivo, sobre o qual nos fundamentamos, sobretudo, nos estudos de Marcuschi (2008), define os domínios como grandes esferas discursivas de caráter flexível, nas quais se localizam os variados gêneros textuais de acordo com suas semelhanças de contexto e de intenção comunicativa.
} 
do Programa Nacional de Alfabetização e Cidadania (PNAC), em 1990, buscando a valorização da carreira docente e o combate ao analfabetismo e a instauração do pacto federativo que previa a gestão do Ensino Fundamental como prioridade de ordem estadual.

Nesse cenário, foram disseminados os Parâmetros Curriculares Nacionais (PCN), documento distribuído na rede pública de ensino. Ao ler o documento, constatamos que, no que tange ao ensino da língua com base em gêneros textuais, os PCN (BRASIL, 1998) propõem que as práticas de leitura e de escrita devem ser consideradas práticas sociais, de modo que confira ao aluno a capacidade de planejar suas construções comunicativas, tomando a linguagem como uma ferramenta de formação cidadã.

Nos Quadros 2 e 3, a seguir, reproduzimos os dados dispostos nos PCN (BRASIL, 1998) a respeito dos gêneros que devem ser idealmente privilegiados durante o percurso escolar dos alunos da rede pública de ensino, organizados e selecionados de acordo com os objetivos principais defendidos no documento para a didatização dos gêneros textuais. No Quadro 2, encontram-se os gêneros privilegiados para a prática de escuta e de leitura de texto; no Quadro 3, os gêneros selecionados para a prática de produção de textos.

QUADRO 2 - Gêneros sugeridos nos PCN para a prática de escuta e leitura de textos

\begin{tabular}{|c|c|c|c|}
\hline \multicolumn{4}{|c|}{$\begin{array}{l}\text { GÉNEROS PRIVILEGIADOS PARA A PRÁTICA DE ESCUTA E LEITURA DE } \\
\text { TEXTOS }\end{array}$} \\
\hline \multicolumn{2}{|c|}{ LINGUAGEM ORAL } & \multicolumn{2}{|c|}{ LINGUAGEM ESCRITA } \\
\hline LITERÁRIOS & $\begin{array}{l}\text {. cordel, causos e similares } \\
\text { texto dramático } \\
\text { canção }\end{array}$ & LITERÁRIOS & $\begin{array}{l}\text { conto } \\
\text { novela } \\
\text { romance } \\
\text {. crônica } \\
\text {. poema } \\
\text {. texto dramático }\end{array}$ \\
\hline DE IMPRENSA & $\begin{array}{l}\text { comentário radiofônico } \\
\text {. entrevista } \\
\text { debate } \\
\text {. depoimento }\end{array}$ & DE IMPRENSA & $\begin{array}{l}\text {. notícia } \\
\text {. editorial } \\
\text {. artigo } \\
\text {. reportagem } \\
\text {. carta do leitor } \\
\text {. entrevista } \\
\text {. charge e tira }\end{array}$ \\
\hline $\begin{array}{l}\text { DE DIVULGAÇÃO } \\
\text { CIENTIÍFICA }\end{array}$ & $\begin{array}{l}\text {. exposição } \\
\text { seminário } \\
\text {. debate } \\
\text {. palestra }\end{array}$ & $\begin{array}{l}\text { DE DIVULGAÇÃO } \\
\text { CIENTIÍFICA }\end{array}$ & $\begin{array}{l}\text {. verbete } \\
\text { enciclopédico } \\
\text { (nota/artigo) } \\
\text { relatório de } \\
\text { experiência } \\
\text {. didático (textos, } \\
\text { enunciados de }\end{array}$ \\
\hline
\end{tabular}




\begin{tabular}{|l|l|l|l|}
\hline & & & $\begin{array}{l}\text { questões }) \\
\text {.artigo }\end{array}$ \\
\hline PUBLICIDADE & . propaganda & PUBLICIDADE & . propaganda \\
\hline
\end{tabular}

Fonte: Adaptado dos PCN (BRASIL, 1998, p. 54).

QUADRO 3 - Gêneros sugeridos nos PCN para a prática de produção de textos

\begin{tabular}{|c|c|c|c|}
\hline \multicolumn{4}{|c|}{ GÊNEROS PRIVILEGIADOS PARA A PRÁTICA DE TEXTOS ORAIS E ESCRITOS } \\
\hline \multicolumn{2}{|c|}{ LINGUAGEM ORAL } & \multicolumn{2}{|c|}{ LINGUAGEM ESCRITA } \\
\hline LITERÁRIOS & $\begin{array}{l}\text { canção } \\
\text { textos dramáticos }\end{array}$ & LITERÁRIOS & $\begin{array}{l}\text {. crônica } \\
\text {. conto } \\
\text {. poema }\end{array}$ \\
\hline DE IMPRENSA & $\begin{array}{l}\text { notícia } \\
\text { entrevista } \\
\text { debate } \\
\text { depoimento }\end{array}$ & DE IMPRENSA & $\begin{array}{l}\text {. notícia } \\
\text {. artigo } \\
\text {. carta do leitor } \\
\text {. entrevista } \\
\end{array}$ \\
\hline $\begin{array}{l}\text { DE DIVULGAÇÃO } \\
\text { CIENTÍFICA }\end{array}$ & $\begin{array}{l}\text {. exposição } \\
\text {. seminário } \\
\text {. debate }\end{array}$ & $\begin{array}{l}\text { DE DIVULGAÇÃO } \\
\text { CIENTÍFICA }\end{array}$ & $\begin{array}{l}\text {.relatório de } \\
\text { experiência } \\
\text {. esquema e resumo de } \\
\text { artigos ou verbetes de } \\
\text { enciclopédia }\end{array}$ \\
\hline
\end{tabular}

Fonte: Adaptado dos PCN (BRASIL, 1998, p. 57).

Como pode ser observado nos quadros anteriores, os PCN não apontam de forma prescritiva os conteúdos que devem ser trabalhados, como faz o CESP (SÃO PAULO, 2012) conforme veremos a seguir, no qual os temas são detalhados e classificados bimestre por bimestre. Nos PCN (BRASIL, 1998), distintamente, as recomendações são estabelecidas de uma forma mais generalizada, abrangendo todo o conteúdo previsto para o Ensino Fundamental, ou seja, da $5^{\underline{a}}$ a $8^{\underline{a}}$ série ou do $6^{\circ}$ ao $9^{\circ}$ ano.

Dessa forma, fica evidente a orientação de que o conteúdo em relação aos gêneros seja variado e amplo, de modo a proporcionar um aprendizado que possibilite o desenvolvimento linguístico dos alunos. A partir dessas recomendações, foi elaborado o CESP (SÃO PAULO, 2012), sobre o qual discorreremos. 


\section{Currículo do Estado de São Paulo}

O Currículo do Estado de São Paulo (CESP), como uma proposta curricular, foi produzido em 2008 pela Secretaria Estadual de Educação de São Paulo. Trata-se de um documento composto de orientações práticas para dar suporte ao trabalho realizado nas salas de aula da rede pública para o Ensino Fundamental e o Ensino Médio, com o objetivo de aumentar o rendimento dos alunos e garantir a qualidade em seu processo de aprendizagem.

Após uma edição atualizada, publicada em 2012, o documento enfatiza o fato de que as práticas de leitura e escrita estão relacionadas não apenas ao conteúdo de Língua Portuguesa, mas também de todas as outras áreas de conhecimento e, por isso, devem ser manuseadas como itens prioritários durante o processo escolar. O CESP (SÃO PAULO, 2012) também aponta que o conhecimento adquirido em sala de aula deve se estender à vida cotidiana, deixando de ser um apanhado de matérias de base puramente acadêmica para ser ferramenta na mobilização da cultura.

Em relação aos conteúdos e habilidades previstos no CESP (SÃO PAULO, 2012) para o 9a ano do Ensino Fundamental, reproduzimos no Quadro 4 as propostas do Governo do estado para o programa de aula, incluindo os conteúdos sugeridos e as habilidades que devem ser idealmente desenvolvidas:

QUADRO 4 - Conteúdos e habilidades previstas para o 9a ano do Ensino Fundamental pelo CESP 


\begin{tabular}{|c|c|c|}
\hline & $\begin{array}{l}\text { Conteúdos gerais } \\
\text { Traços característicos de textos argumentativos } \\
\text { Traços característicos de textos expositivos } \\
\text { Estudos de gêneros da tipologia argumentativa } \\
\text { Estudos de gêneros da tipologia expositiva } \\
\text { Argumentar e expor: semelhanças e diferenças } \\
\text { Estudos linguísticos: } \\
\text { - Marcas dêiticas (pronomes pessoais) } \\
\text { - Pontuação } \\
\text { - Elementos coesivos (preposição e conectivos) } \\
\text { - Concordâncias nominal e verbal } \\
\text { - Questões ortográficas } \\
\text { - Pronome relativo } \\
\text { - Adequação vocabular } \\
\text { - Período simples } \\
\text { - Crase } \\
\text { Variedades linguísticas } \\
\text { Conteúdos de leitura, escrita e oralidade } \\
\text { Leitura, produção e escuta de textos argumentativos e } \\
\text { expositivos em diferentes situações de comunicação } \\
\text { Interpretação de textos literário e não literário } \\
\text { - Leitura em voz alta } \\
\text { - Inferência } \\
\text { - Coerência } \\
\text { - Earagrafaçãa } \\
\text { - Elabas de elaboração de fichãas e revisão da escrita } \\
\text { Apresentação oral } \\
\text { Roda de conversa }\end{array}$ & $\begin{array}{l}\text { Espera-se que, tendo como referência principal as } \\
\text { tipologias argumentativa e expositiva, em situações de } \\
\text { aprendizagem orientadas por projetos de leitura e escrita } \\
\text { e centradas em debate regrado, textos de opinião, artigo } \\
\text { de divulgação científica e outros gêneros dessas } \\
\text { tipologias, os estudantes desenvolvam as seguintes } \\
\text { habilidades: } \\
\text { - Ler e interpretar textos argumentativos, inferindo seus } \\
\text { traços característicos } \\
\text { - Analisar textos argumentativos e construir quadros- } \\
\text { síntese } \\
\text { - Analisar a norma-padrão em funcionamento no texto } \\
\text { - Debater oralmente sobre temas variados, selecionando } \\
\text { argumentos coerentes para a defesa de um dado ponto } \\
\text { de vista } \\
\text { - Identificar tipos de argumentos em textos de opinião } \\
\text { - Produzir resenhas utilizando os conhecimentos } \\
\text { adquiridos sobre textos argumentativos } \\
\text { - Analisar temas diversos, selecionando argumentos que } \\
\text { justifiquem pontos de vista divergentes } \\
\text { - Fruir esteticamente objetos culturais } \\
\text { - Saber revisar textos, reconhecendo a importânciadas } \\
\text { questões linguísticas para a organização coerente de } \\
\text { ideias e argumentos }\end{array}$ \\
\hline 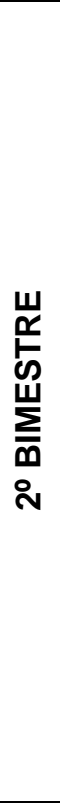 & $\begin{array}{l}\text { Conteúdos gerais } \\
\text { Estudo de gêneros textuais da tipologia argumentativa } \\
\text { Estudo de gêneros textuais da tipologia expositiva } \\
\text { Gênero textual artigo de opinião } \\
\text { Gênero textual carta do leitor } \\
\text { Estudos linguísticos: } \\
\text { - Pontuação } \\
\text { - Figuras de linguagem } \\
\text { - Colocação pronominal } \\
\text { - Regências verbal e nominal } \\
\text { - Funções da linguagem } \\
\text { - Período composto por coordenação } \\
\text { - Articuladores sintáticos argumentativos } \\
\text { Variedades linguísticas } \\
\text { Conteúdo de leitura, escrita e oralidade } \\
\text { Leitura, produção e escuta de artigo de opinião, carta do } \\
\text { leitor e outros gêneros em diferentes situações de } \\
\text { comunicação } \\
\text { - Formulação de hipótese } \\
\text { - Inferência } \\
\text { - Interpretação de textos literários e não literários } \\
\text { - Informatividade } \\
\text { Etapas de elaboração e revisão da escrita } \\
\text { Roda de conversa }\end{array}$ & $\begin{array}{l}\text { Espera-se que, tendo como referência principal as } \\
\text { tipologias argumentativa e expositiva, em situações de } \\
\text { aprendizagem orientadas por projetos de leitura escrita } \\
\text { e centradas em debate regrado, textos de opinião, artigo } \\
\text { de divulgação científica e outros gêneros dessas } \\
\text { tipologias, os estudantes desenvolvam as seguintes } \\
\text { habilidades: } \\
\text { - Ler e interpretar textos expositivos e argumentativos, } \\
\text { inferindo seus traços característicos } \\
\text { - Selecionar informações de acordo com os objetivos ou } \\
\text { intencionalidades da situação comunicativa } \\
\text { - Identificar, escolher e classificar argumentos que sejam } \\
\text { a favor ou contrários à defesa de um ponto de vista } \\
\text { - Analisar imagens do ponto de vista de seu caráter } \\
\text { político } \\
\text { - Analisar a norma-padrão em funcionamento no texto } \\
\text { - Compreender, identificar e utilizar os mecanismos de } \\
\text { coerência e coesão no texto } \\
\text { - Construir parágrafos argumentativos de acordo com o } \\
\text { contexto da situação comunicativa } \\
\text { - Criar hipótese de sentido a partir de informações } \\
\text { encontradas no texto } \\
\text { - Fruir esteticamente objetos culturais }\end{array}$ \\
\hline
\end{tabular}




\begin{tabular}{|c|c|c|}
\hline 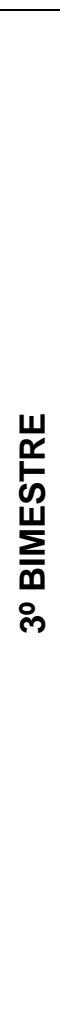 & $\begin{array}{l}\text { Conteúdos gerais } \\
\text { Discurso político: diferentes formas de representação } \\
\text { Estudo de tipologia e gêneros argumentativos articulados } \\
\text { por projetos } \\
\text { Construção de projeto político } \\
\text { Estudos linguísticos: } \\
\text { - Regências verbal e nominal } \\
\text { - Período composto por subordinação } \\
\text { - Conjunção } \\
\text { - Preposição } \\
\text { - Anafóricos } \\
\text { - Pontuação } \\
\text { - Período composto } \\
\text { Variedades linguísticas } \\
\text { Conteúdo de leitura, escrita e oralidade } \\
\text { Leitura, escrita e escuta intertextual e interdiscursiva de } \\
\text { gêneros argumentativos e expositivos articulados por } \\
\text { projeto político } \\
\text { - Interpretação de textos literário e não literário } \\
\text { - Inferência } \\
\text { - Fruição } \\
\text { - Lituacionalidade } \\
\text { - Leitura dramática em voz alta } \\
\text { - Coerência } \\
\text { - Coesão } \\
\text { - Lnformatividade } \\
\text { voz, elocuçãa e pausa } \\
\text { - Etapas de elaboração e revisão da escrita } \\
\text { Paragrafação }\end{array}$ & $\begin{array}{l}\text { Espera-se que, tendo como referência principal as } \\
\text { tipologias argumentativa e expositiva, em situações de } \\
\text { aprendizagem orientadas por projetos de leitura e escrita } \\
\text { e centradas em debate regrado, textos de opinião, artigo } \\
\text { de divulgação científica e outros gêneros dessas } \\
\text { tipologias, os estudantes desenvolvam as seguintes } \\
\text { habilidades: } \\
\text { - Identificar, escolher e classificar argumentos que sejam } \\
\text { a favor ou contrários à defesa de um ponto de vista } \\
\text { - Analisar a norma-padrão em funcionamento no texto } \\
\text { - Identificar e reconhecer a produção de um texto como } \\
\text { processo em etapas de reelaboração } \\
\text { - Produzir versão final de um texto com marcas de } \\
\text { intervenção } \\
\text { - Construir ponto de vista que represente o interesse do } \\
\text { grupo majoritário } \\
\text { - Construir conceito de "ato político" a partir de situação } \\
\text { de comunicação } \\
\text { - Construir opinião crítica a partir de informações e } \\
\text { análises apresentadas } \\
\text { - Analisar imagens sob o ponto de vista de seu caráter } \\
\text { político e social } \\
\text { - Realizar apresentação oral adequada à situação de } \\
\text { interlocução } \\
\text { - Fruir esteticamente objetos culturais }\end{array}$ \\
\hline 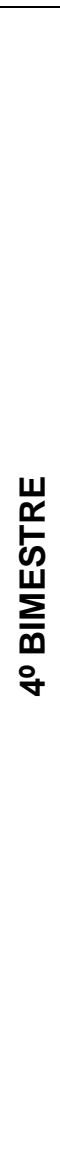 & $\begin{array}{l}\text { Conteúdos gerais } \\
\text { Discurso político: diferentes formas de representação } \\
\text { Estudo de tipologia e gêneros argumentativos articulados } \\
\text { por projetos } \\
\text { Construção de projeto político } \\
\text { Estudos linguísticos: } \\
\text { - Pontuação } \\
\text { - Período composto por subordinação } \\
\text { - Conjunção } \\
\text { - Crase } \\
\text { - Regências verbal e nominal } \\
\text { - Concordâncias verbal enominal } \\
\text { Variedades linguísticas } \\
\text { Conteúdo de leitura, escrita e oralidade } \\
\text { Leitura, escrita e escuta intertextual e interdiscursiva de } \\
\text { gêneros argumentativos e expositivos articulados por } \\
\text { projeto político } \\
\text { - Interpretação de textos literário e não literário } \\
\text { - Inferência } \\
\text { - Fruição } \\
\text { - Situacionalidade } \\
\text { - Leitura dramática } \\
\text { - Leitura em voz alta } \\
\text { - Coerência } \\
\text { - Coesão } \\
\text { - Informatividade } \\
\text { - Leitura oral: ritmo, entonação, respiração, qualidade da } \\
\text { voz, elocução e pausa } \\
\text { - Etapas de elaboração e revisão da escrita } \\
\text { - Paragrafação }\end{array}$ & $\begin{array}{l}\text { Tendo como referência principal as tipologias } \\
\text { argumentativa e expositiva em situações de } \\
\text { aprendizagem orientadas por projetos de leitura e escrita } \\
\text { e centradas em debate regrado, textos de opinião, artigo } \\
\text { de divulgação científica e outros gêneros dessas } \\
\text { tipologias, espera-se que os estudantes desenvolvam as } \\
\text { seguintes habilidades: } \\
\text { - Reconhecer e analisar texto de estrutura opinativa } \\
\text { - Resumir texto opinativo } \\
\text { - Posicionar-se como agente de ações que contribuam } \\
\text { para sua formação como leitor, escritor e ator em uma } \\
\text { dada realidade } \\
\text { - Reformular ideias, apresentando novos argumentos e } \\
\text { exemplos } \\
\text { - Analisar a norma-padrão em funcionamento no texto } \\
\text { - Utilizar conhecimento sobre a língua (linguísticos, de } \\
\text { gênero etc.) para elaborar projeto coletivo } \\
\text { - Produzir uma versão final de um texto com marcas de } \\
\text { intervenção } \\
\text { - Fruir esteticamente de objetos culturais } \\
\text { Competências de produção de textos (SARESP) } \\
\text { COMPETÊNCIA I - Tema - Desenvolver o texto de } \\
\text { acordo com as determinações temáticas e situacionais } \\
\text { da proposta de produção de texto } \\
\text { COMPETÊNCIA II - Tipologia - Mobilizar, no texto } \\
\text { produzido, os conhecimentos relativos aos elementos } \\
\text { organizacionais da tipologia textual em questão } \\
\text { COMPETÊNCIA III - Coesão/Coerência - Organizar o } \\
\text { texto de forma lógica, demonstrando conhecimento dos } \\
\text { mecanismos coesivos linguísticos e textuais necessários } \\
\text { para a construção coerente do texto } \\
\text { COMPETÊNCIA IV - Registro - Adequar as convenções } \\
\text { e normas do sistema da escrita à situação comunicativa } \\
\text { COMPETÊNCIA V - Proposição - Elaborar proposta de } \\
\text { intervenção para o problema abordado, demonstrando } \\
\text { um posicionamento crítico e cidadão a respeito do tema }\end{array}$ \\
\hline
\end{tabular}

Fonte: Adaptado pelo autor a partir do Currículo do Estado de São Paulo (2012, p. 70 -

77). 
Com base nesses dados, pode-se inferir que o conteúdo prioritário para o 9 do Ensino Fundamental são as construções linguísticas relacionadas aos gêneros da ordem do argumentar e do expor, incluindo as características fundamentais das tipologias argumentativa e expositiva, sua interpretação e produção discursiva.

\section{Análise do Corpus}

Para dar início às análises do corpus deste estudo, partimos das concepções bakhtinianas, retomadas por Marcuschi (2008), de que o texto está muito além de uma estrutura meramente formal e deve ser compreendido como um instrumento vivo de comunicação, refletindo uma organização sociocultural e histórica. Na esteira desse pensamento, defendemos que, a fim de cumprir seus objetivos prioritários, um programa escolar deve garantir, basicamente, que o estudante desenvolva a capacidade linguística de reconhecer as diferentes estruturas de gêneros textuais, bem como tenha o conhecimento necessário para a escolha do gênero adequado aos diversos contextos e situações comunicativas.

A fim de identificar os gêneros textuais propostos pelo material didático e sua predominância, realizamos a identificação do número de ocorrências de cada gênero a partir do quadro geral proposto por Marcuschi (2008), conforme apresentado neste estudo no Quadro 1.

$\mathrm{Na}$ Tabela 1 , elencamos os gêneros textuais e a quantidade de ocorrências de cada um deles encontrada no CALP - volume 1, material para o estudo da Língua Portuguesa durante os dois primeiros bimestres do 9ำ ano.

TABELA 1 - Gêneros Textuais - CALP 9 ano - Vol. 1

\begin{tabular}{l|c}
\hline \multicolumn{1}{c|}{ Gênero Textual } & $\begin{array}{c}\text { Ocorrência } \\
\text { VOLUME 1 }\end{array}$ \\
\hline Artigo de divulgação científica & 02 \\
Verbete de enciclopédia & 02 \\
Resenha & 01 \\
Relatório & 01 \\
Notícia & 01 \\
Reportagem & 02 \\
Artigo de opinião & 01 \\
Anúncio classificado & 01 \\
Tira de cartoon & 01
\end{tabular}




\begin{tabular}{l|c} 
Entrevista & 01 \\
Propaganda & 01 \\
Carta & 02 \\
Poema & 01 \\
Conto & 02 \\
Romance (trecho) & 01 \\
Crônica & 02 \\
\hline & TOTAL DE \\
TOTAL DE GÊNEROS: 16 & OCORRÊNCIAS: \\
\hline
\end{tabular}

Fonte: Elaboração própria.

Em um primeiro momento, constatamos que são trabalhados 16 gêneros textuais, que aparecem num total de 22 vezes no decorrer da publicação. Quase todos os gêneros são abordados uma única vez; os gêneros trabalhados em mais de uma ocasião, como o artigo de divulgação científica, o verbete de enciclopédia, a reportagem, a carta, o conto e a crônica, são abordados apenas uma vez mais. Dessa forma, observamos que o número de gêneros efetivamente trabalhados com os alunos é menor do que o número de ocorrências, não havendo, em alguns momentos, uma sistematização acerca do aprendizado do gênero.

Partindo desses dados, embora tenhamos percebido alguns avanços nos padrões de ensino da Língua Portuguesa, que, até alguns anos, priorizava somente o estudo de grandes obras de gêneros consagrados, como o romance e o poema, ainda é necessário avançar mais, principalmente se levarmos e m conta a dinamicidade do mundo contemporâneo e a necessidade de um trabalho sistematizado do gênero.

A variedade dos gêneros textuais é relevante para o aprendizado mais efetivo e para o refinamento das habilidades discursivas dos alunos, pois, como discutido anteriormente, um texto não existe por si só, tal como afirma Koch (1996), visto que toda forma de produção textual faz referência a outras, seja de forma consciente ou inconsciente por parte do agente enunciador. A exemplo do que ocorre nas interações sociais, em que há uma gama de possibilidades de discurso, com adaptações específicas para cada contexto, com alterações originadas do produtor e também do receptor, de acordo com os seus objetivos específicos em dada situação comunicacional, no que concerne aos gêneros textuais não é diferente e nem há como sê-lo, uma vez 
que eles refletem diretamente as relações sociais reais e se inserem em diferentes situações de comunicação.

Outro tópico a ser considerado é a apresentação única do gênero, ou, no máximo, repetida apenas uma vez, condição esta que pode comprometer a compreensão do gênero textual estudado. Desse modo, a fim de que o aluno tenha as condições necessárias para compreender o conteúdo e estabelecer as relações linguísticas esperadas e não estudar o gênero como um único modelo possível, é preciso conceber o texto como uma prática social que pode orientar a ação pedagógica, privilegiando o contato real do estudante com a multiplicidade de gêneros que circulam socialmente (PARANÁ, 2006).

Tendo justificado a necessidade de maior sistematização dos gêneros no material utilizado no ensino da Língua Portuguesa, voltamos nossa atenção para outro ponto que, a nosso ver, merece destaque neste estudo. Identificamos, em nossa tabulação de dados, a existência de alguns gêneros que não se enquadram no quadro geral ${ }^{2}$ proposto Marcuschi (2008) e que também foram trabalhados no material, conforme demonstrado na Tabela 2.

TABELA 2 - Gêneros Textuais não Elencados no Quadro Geral Proposto por Marcuschi (2008) - CALP 9o ano - Vol. 1

\begin{tabular}{l|c}
\hline \multicolumn{1}{c|}{ Gênero Textual } & $\begin{array}{c}\text { Ocorrência } \\
\text { VOLUME 1 }\end{array}$ \\
\hline Exposição oral $^{3}$ & 02 \\
Debate regrado $^{4}$ & 01 \\
Letra de música $^{5}$ & 02 \\
\hline TOTAL DE GÊNEROS: 03 & TOTAL DE \\
OCORRÊNCIAS: \\
\hline
\end{tabular}

\footnotetext{
${ }^{2}$ O quadro geral de Marcuschi (2008, p. 194-196) é uma proposta, logo, flexível e "[...] resta dizer que muitos gêneros são comuns a vários domínios" (MARCUSCHI, 2008, p. 194).

${ }^{3}$ Costa (2014), no livro Dicionário de Gêneros Textuais, afirma que há muita confusão entre os gêneros exposição oral e seminário, uma vez que, comumente, o gênero exposição oral é considerado como sinônimo de seminário.

${ }^{4}$ Segundo Costa (2014), o debate (colóquio, conversa/conversação, diálogo, discussão, fórum ou fórum virtual) no cotidiano, trata-se de uma discussão acirrada, altercação, contenda por meio de palavras ou argumentos ou exposição de razões em defesa de uma opinião ou contra um argumento, ordem, decisão etc. Pertencendo mais comumente à comunicação oral, em todos seus tipos, predomina a linguagem argumentativa e/ou expositiva.

${ }^{5}$ De acordo com Costa (2014), a composição é qualquer produção literária, musical, artística e, por extensão de sentido, passou a ser um gênero usado na escola como exercício escrito, literário ou não, que consiste no desenvolvimento, pelos alunos, de um tema proposto pelo professor. Desse modo, entendemos que letra de música (canção) seja composição musical, por isso, a enquadramos como gênero textual.
} 


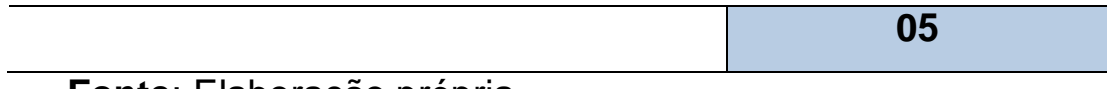

Fonte: Elaboração própria.

Foram explorados 03 gêneros característicos da expressão oral: a exposição oral propriamente dita, indicada em 2 atividades, nas quais os alunos deveriam transcrever um áudio gravado e discuti-lo, bem como 01 ocorrência do debate regrado; 02 ocorrências de letra de música.

Marcuschi (2008) já havia sinalizado isso, demonstrando que, aos poucos, a tradição no ensino da língua, no campo estritamente escrito, vem abrindo espaço para novas perspectivas no que concerne à modalidade oral. No entanto, o teórico afirma que "[...] os gêneros orais em geral ainda não são tratados de modo sistematizado. Apenas alguns, de modo particular os mais formais, são lembrados em suas características mais básicas" (MARCUSCHI, 2008, p. 207). Essa tendência está diretamente relacionada ao contexto cultural de ensino e o próprio autor acentua que, se fôssemos fazer um levantamento de gêneros considerando outras culturas, "[...] teríamos grandes surpresas. Pois, há culturas em que a situação se inverteria totalmente em relação ao que se tem nesses quadros" (MARCUSCHI, 2008, p. 196). No Brasil, há um histórico de priorização de gêneros mais tradicionais nas salas de aula e é precisamente por isso que a abertura para novos gêneros orais vêm acontecendo de forma gradual.

Dolz e Schneuwly (2004) definem a exposição oral como um gênero textual público, relativamente formal e específico, no qual um expositor especialista dirige-se a um auditório, de modo (explicitamente) estruturado, para the transmitir informações, descrever-Ihe ou the explicar alguma coisa sobre um determinado assunto. Ou seja, o gênero exposição oral não é uma discussão coletiva, o discurso se caracteriza como monologal. Realizado também em sala de aula, o expositor dirige-se ao público para Ihe transmitir informações, descrever-lhe ou explicar-Ihe algum assunto. Já o seminário, segundo Bezerra (2003), é um gênero de discussão oral, coletiva, realizada em sala de aula, como a intenção de explorar de forma aprofundada um determinado assunto. Para isso, os participantes devem ter lido, com antecedência, o material escrito sobre esse assunto, devendo seguir um roteiro 
com os tópicos a serem discutidos, ouvir e anotar informações, se posicionar a respeito, para encerrar com uma avaliação (que pode ser por escrito ou oralmente). Diante do exposto, nota-se que o seminário e a exposição oral sejam dois gêneros assemelhados e que, portanto, cabe aos professores delimitar as características de cada um deles para melhor trabalhá-los.

Além disso, para Costa (2014), o gênero debate regrado coloca em jogo capacidades humanas fundamentais sob o ponto de vista i) linguístico, como as técnicas de retomada do discurso do outro, marcas de refutação etc.; ii) cognitivo, como as capacidades crítica e social (escuta e respeito pelo outro); e iii) individual, como as habilidades de se situar, de tomar posição, de construção de identidade. Entre outros, podem-se destacar alguns tipos de debate: a) debate de opinião de fundo controverso: visa à compreensão de um assunto controverso (por exemplo, "A favor ou contra a clonagem de seres vivos"), já que possui várias facetas ou permite várias posições e pode também influenciar a posição do outro, como também precisar/forjar ou transformar/modificar a própria opinião; b) debate deliberativo: propõe-se, após a discussão de um tema (por exemplo, "Realizar uma festa de formatura" ou "Escolher um lugar para passear") que permite a explicitação e exposição de motivos de cada participante, à tomada de uma decisão que pode estabelecer soluções originais para algo que era anteriormente polêmico; c) debate para resolução de problemas: valendo-se de um conhecimento comum dos debatedores (por exemplo, "Eclipse lunar", "Reprodução humana"), cuja solução existe, mas não é totalmente conhecida, de modo que o grupo deve construir uma proposta de solução com base nas contribuições de cada debatedor; d) debate público regrado: os debates podem ter uma forma livre, e cada debatedor expressa o que pensa e o que acha sobre o tema, ou podem também ter regras (debate regrado), com a presença de um moderador que assegura o papel de síntese, de reenfoque, de reproposição, não permitindo uma dispersão desnecessária. Esse é um modelo de debate muito comum, usado pelos meios de comunicação em época de eleições.

Na sequência, analisamos os dados obtidos no volume 2 da publicação e organizamos os gêneros textuais presentes no segundo volume do CALP, 
material de estudo dedicado aos dois últimos bimestres do 9ำano, conforme Tabela 3.

TABELA 3 - Gêneros Textuais - CALP 9ำ ano - Vol. 2

\begin{tabular}{l|c}
\hline \multicolumn{1}{c|}{ Gênero Textual Escrito } & $\begin{array}{c}\text { Ocorrência } \\
\text { VOLUME 2 }\end{array}$ \\
\hline Artigo de divulgação científica & 01 \\
Resumo & 01 \\
Manual/Roteiro instructional & 02 \\
Reportagem & 03 \\
Artigo de opinião & 02 \\
Conto & 01 \\
Romance (trecho) & 02 \\
\hline \multirow{2}{*}{ TOTAL DE GÊNEROS: $\mathbf{0 7}$} & TOTAL DE \\
& OCORRÊNCIAS: \\
\hline
\end{tabular}

Fonte: Elaboração própria.

Em comparação com o volume 1, a segunda publicação apresenta um número inferior de ocorrências de gêneros textuais, pois somente 7 foram trabalhados num total de 12 ocorrências, sendo que o gênero reportagem foi estudado 3 vezes.

No segundo volume do CALP, a modalidade de artigo de opinião é estudada. Embora o gênero em si tenha sido explorado somente 2 vezes no decorrer da publicação, sua premissa principal - a tipologia argumentativa - é trabalhada de forma escrita e oral em debates entre os alunos sobre temas polêmicos da atualidade, conforme discorreremos mais adiante quando nos dedicarmos à análise das atividades propostas no material. Importa lembrar que não identificamos, na segunda publicação, a existência de gêneros textuais não encontrados no quadro de Marcuschi (2008).

De modo geral, o segundo volume do CALP apresenta menor número de gêneros textuais que o primeiro. Constatamos que o material dedicado ao segundo semestre prioriza atividades acerca de um mesmo gênero proposto em cada situação de aprendizagem, principalmente de construção de um roteiro de viagem, de debates e produção de escrita, de problemáticas de uma formatura do Ensino Fundamental e da realização de uma semana de profissões na escola.

Em seguida, fizemos um levantamento comparativo entre os dados obtidos nos dois volumes do CALP, conforme Tabela 4, na qual estão 
tabulados os números referentes aos volumes 1 e 2 e o total de recorrências de cada gênero textual abordado no corpus estudado.

TABELA 4 - Recorrência Total dos Gêneros Textuais - CALP 9 ano

\begin{tabular}{l|c|c|c}
\hline \multicolumn{1}{c|}{ Gênero Textual } & $\begin{array}{c}\text { Recorrência } \\
\text { VOLUME 1 }\end{array}$ & $\begin{array}{c}\text { Recorrência } \\
\text { VOLUME 2 }\end{array}$ & $\begin{array}{c}\text { Total de } \\
\text { Recorrências }\end{array}$ \\
\hline Artigo de divulgação científica & 02 & 01 & 03 \\
Verbete de enciclopédia & 02 & - & 02 \\
Resumo & - & 01 & 01 \\
Resenha & 01 & - & 01 \\
Manual/Roteiro instrucional & - & 02 & 02 \\
Relatório & 01 & - & 01 \\
Notícia & 01 & - & 01 \\
Reportagem & 02 & 03 & 05 \\
Anúncio classificado & 01 & - & 01 \\
Artigo de opinião & 01 & 02 & 03 \\
Tira de cartoon & 01 & - & 01 \\
Entrevista & 01 & - & 01 \\
Propaganda & 01 & - & 01 \\
Carta & 02 & - & 02 \\
Poema & 01 & - & 01 \\
Conto & 02 & 01 & 03 \\
Romance (trecho) & 01 & 02 & 03 \\
Crônica & 02 & - & 02 \\
Exposição oral & 02 & - & 02 \\
Debate regrado & 01 & - & 01 \\
Letra de música & 02 & - & 02 \\
\hline TOTAL DE GËNEROS: $\mathbf{2 1}$ & $\mathbf{2 7}$ & $\mathbf{1 2}$ & $\mathbf{3 9}$ \\
\hline
\end{tabular}

Fonte: Elaboração própria.

Somando-se os dados obtidos no levantamento dos gêneros textuais abordados nos dois volumes do CALP, tem-se 21 gêneros explorados em meio a um total de 39 recorrências. Com isso, constatamos que os gêneros com maior recorrência de tratamento são em ordem decrescente por número de abordagens: reportagem, com 05 ocorrências; e conto, romance (trecho), artigo de divulgação científica e artigo de opinião, com 03 ocorrências cada.

O gênero mais estudado é o da reportagem. Esse gênero aponta para uma preocupação com 0 fato de que os alunos formados no Ensino Fundamental carreguem consigo um conhecimento de gênero atual e recorrente em nosso cotidiano. A leitura atenta de reportagens jornalísticas pode auxiliar na conscientização cidadã no que concerne ao papel do estudante como agente transformador da sociedade. 
O artigo de divulgação científica é apresentado em três momentos distintos no decorrer do material, e sua abordagem se apoia na necessidade de que os alunos ingressem na próxima etapa da vida escolar - o ensino médio, com uma base do que seriam os gêneros acadêmicos. Além disso, os gêneros conto e romance aparecem em três momentos, já sendo consagrados no ensino da Língua Portuguesa e cumprindo seu papel de gênero tradicional.

A partir do levantamento realizado, podemos afirmar que, embora tenha havido certo avanço na formatação do material, servindo como instrumento de suporte das aulas durante todo o último ano do ciclo fundamental de estudos, há ainda muito a ser feito, sobretudo no que tange ao avanço das tecnologias virtuais.

É importante ressaltar, ainda, que, apesar de estarmos absolutamente imersos e dependentes das mídias virtuais, e mesmo os alunos fazendo uso das novas tecnologias, não foram encontrados, em nenhum dos dois volumes do CALP, uma abordagem textual do que Marcuschi e Xavier (2010) definem como "gêneros emergentes" - em outras palavras, gêneros digitais.

Os gêneros textuais identificados nas mídias virtuais são, muitas vezes, adaptados a partir de gêneros já consagrados, que sofrem uma espécie de evolução para se enquadrarem no uso digital. A respeito disso, Pimentel (2010, p. 2) explica que "[...] os gêneros textuais já convencionados pela sociedade são transportados para o novo meio de comunicação - a Internet - sofrendo algumas adaptações relativas ao espaço virtual".

Como observa Thomas Erickson ${ }^{6}$ (1997, p. 4 apud MARCUSCHI, 2008, p. 198, grifo do autor), "[...] a interação on-line tem o potencial de acelerar enormemente a evolução dos gêneros". Ora, se tais gêneros são tão presentes em nosso cotidiano e possuem tamanho potencial transformador na evolução da estrutura linguística, podemos nos questionar por que ainda não foram inseridos num plano de estudo tão fundamental. A resposta para essa pergunta

${ }^{6}$ ERICKSON, T. Social Interaction on the Net: Virtual Community as participatory Genre.Publicado no Proceedings of the Thirtieth Hawaii International Conference on System Science. Maui, Hawaii. January, Vol. VI, p. 13-21, 1997. Disponível em:<http://www.pliant.org/personal/Tom_Erickson/VC_as_Genre.html>. Acesso em: 30 de jun. 2018. 
talvez consista na forte resistência à aceitação de que e-mails, chats, blogs etc. se enquadrem como modelos oficiais de gêneros textuais.

Partindo de tais fatos, pensamos ser necessária uma comutação nos modelos de ensino, a fim de que haja espaço para discussão e análise das estruturas textuais de mídias digitais ${ }^{7}$. Levando em conta tais aspectos, há que se questionar por que tais gêneros não foram incorporados ao material em estudo.

\section{Considerações Finais}

Ao idealizar esta pesquisa, partimos das discussões acerca dos gêneros textuais, após a publicação dos PCN - Parâmetros Curriculares Nacionais em 1998, nos quais está explícita a preocupação com o ensino da Língua Portuguesa com base em gêneros textuais. Essa preocupação começou a se tornar maior a partir da leitura da teoria bakhtiniana e, no cenário nacional, com os pressupostos marcuschianos de que os gêneros textuais são entidades sociocomunicativas e com vivo poder de mudança nas esferas culturais, de forma a promover uma real interação linguística.

Considerando tais proposições, optamos por tomar como corpus de estudo os Cadernos do Aluno de Língua Portuguesa do $9^{\circ}$ ano do Ensino Fundamental, apostilas com situações de aprendizagem. Esse material nos permitiu analisar pontos importantes acerca da questão dos gêneros textuais, bem como refletir sobre uma lacuna existente no apostilado ao não considerar o nosso próprio mundo, o mundo virtual. Sendo uma modalidade em franco desenvolvimento, poder interacional e potencial transformador das estruturas linguísticas, observamos que os gêneros digitais ainda não foram incorporados pelo CALP utilizado como apoio para as aulas no decorrer do ano letivo.

É preciso considerar a importância dos elementos virtuais na cultura contemporânea e a necessidade de adequação da escola ao mundo virtual,

\footnotetext{
${ }^{7}$ Em 1998 os PCN já chamavam atenção para os usos das tecnologias da informação ao afirmar que a presença crescente dos meios tecnológicos na vida cotidiana coloca, para a sociedade em geral e para a escola em particular, a tarefa de educar crianças e jovens para a recepção desses meios, ou seja, "conhecer a linguagem videotecnológica própria desse meio" (BRASIL, 1998, p.89).
} 
que transformou a forma como nos relacionamos. É necessário, portanto, que o apostilado não fique alheio a esse processo, pois é de fundamental importância que o aluno saiba identificar, relacionar e compreender os diversos gêneros, a fim de que seja plenamente letrado.

Notamos a inserção majoritária de gêneros narrativos, tendência que acompanha os materiais utilizados no ensino da Língua Portuguesa de forma geral, haja vista que são tradicionalmente explorados com maior frequência no decorrer da vida escolar. Acreditamos que essas estruturas narrativas poderiam ser utilizadas como estímulo para a introdução das tipologias argumentativas.

A tipologia textual da ordem do descrever foi a que teve menor número de incidências ao longo do apostilado; no primeiro volume, sequer foi introduzida. Já as tipologias da ordem do relatar, argumentar e expor, embora tenham aparecido, foram pouco exploradas. Esse é um aspecto que aponta para a necessidade de reparar o conteúdo do CALP, especialmente se levarmos em consideração que, segundo o CESP, no $9^{\circ}$ do Ensino Fundamental, deveria ser aprofundado o estudo de textos argumentativos e expositivos.

De maneira geral, consideramos positiva a existência de um recurso como o CALP para o apoio em sala de aula, em especial como instrumento de unificação do ensino, pois todos os alunos da rede pública têm contato com a mesma estrutura curricular de aprendizagem, o que reduz disparidades nos indicadores de desempenho devido às diferenças geográficas, étnico-raciais e sociais dentro do estado de São Paulo.

\section{Referências}

BAKHTIN, M. Estética da criação verbal. Trad. Paulo Bezerra. 6. ed. São Paulo: Martins Fontes, 2011 [1979].

BEZERRA, M. A. Seminário, mais que uma técnica de ensino: um gênero textual. In: NOME DO EVENTO, número do evento, 2003, cidade. Título da publicação do evento. Cidade: Editora, 2003.

BRASIL. Parâmetros Curriculares Nacionais - PCN (5aa a 8 séries). Brasília: MEC/SEF, 1998. 
BRONCKART, J. P. Atividade de linguagem, textos e discursos: por um interacionismo sócio-discursivo. Trad. Anna Rachel Machado e Péricles Cunha. 2. ed. São Paulo: EDUC, 2012 [1997].

COSTA, S. R. Dicionário de gêneros textuais. 3. ed. rev. ampl. Belo Horizonte: Autêntica Editora, 2014.

DOLZ, J.; NOVERRAZ, M.; SCHNEUWLY, B. Sequências didáticas para o oral e a escrita: apresentação de um procedimento. In: SCHNEUWLY, B.; DOLZ, J. Gêneros orais e escritos na escola. Trad. e org. Roxane Rojo e Glaís Sales Cordeiro. Campinas: Mercado de Letras, 2004.

DOLZ, J.; SCHNEUWLY, B. Gêneros orais e escritos na escola. Trad. e org. Roxane Rojo e Glaís Sales Cordeiro. Campinas: Mercado de Letras, 2004.

$\mathrm{KOCH}$, I. G. V. Estratégias pragmáticas de processamento textual. Caderno de Estudos Linguísticos, Campinas, n. 30, jan./jun. 1996.

MARCUSCHI, L. A. Produção textual, análise de gêneros e compreensão. São Paulo: Parábola, 2008.

. Gêneros textuais: definição e funcionalidade. In DIONÍSIO, A. P.; $\overline{M A C H A} D O, A$. R.; BEZERRA, M. A. Gêneros textuais \& ensino. Rio de Janeiro: Lucerna, 2007.

. Gêneros textuais: configuração, dinamicidade e circulação. In:

KARWOSKI, A. M.; GAYDECZKA, B.; BRITO, K. S. (orgs.). Gêneros Textuais: reflexões e ensino. União da Vitória/PR: Kaygangue, 2005.

MARCUSCHI, L. A.; XAVIER, A. C. Hipertexto e gêneros digitais: novas formas de construção de sentido. 3. ed. São Paulo: Cortez, 2010.

PARANÁ. Secretaria de Estado de Educação. Superintendência de Educação. Diretrizes Curriculares de Língua Portuguesa para a Educação Básica do Estado do Paraná. Curitiba: SEED, 2006.

PIMENTEL, C. A escrita íntima na internet: do diário ao blog pessoal. UERJ, 2010. Disponível em:

<http://www.omarrare.uerj.br/numero14/pdf/CARMEM_PIMENTEL.pdf>. Acesso em: 22 jan. 2017.

SÃO PAULO. Secretaria da Educação. Currículo do Estado de São Paulo: linguagens, códigos e suas tecnologias. Coordenação geral: Maria Inês Fini; Coordenação de área: Alice Vieira. 2. ed. São Paulo: SEE, 2012. 


\section{Sobre o autor}

\section{Paulo Roberto Barbosa}

É Doutorando e Mestre em Língua Portuguesa pela Pontifícia Universidade Católica de São Paulo (PUC-SP), ambos sob orientação da Profa. Dra. Leonor Lopes Fávero. Possui graduação em Letras pela Universidade de Mogi das Cruzes (2006) e Pedagogia pela Universidade Nove de Julho (2012). Especializou-se em pós-graduação lato sensu em Tecnologia em Educação a Distância pela Universidade Cidade de São Paulo (2013) e Psicopedagogia Institucional pela Universidade Cidade de São Paulo (2014). Atualmente é Gestor Escolar, efetivo - Secretaria Municipal de Educação de Poá e cursa especialização em Gestão da Educação Pública pela Universidade Federal de São Paulo. Seus interesses de pesquisa são: linguística textual, gênero textual, tipologia argumentativa, interacionismo sociodiscursivo, ensino/aprendizagem de língua portuguesa, sequência didática, gestão escolar e análise de material didático. 